\title{
Antioxidant activity screening of seven Indonesian herbal extract
}

\author{
JOHAN SUKWEENADHI ${ }^{1}$, OEKE YUNITA ${ }^{2}$, FINNA SETIAWAN ${ }^{2}$, KARTINI $^{2}$, MAYA THERESA SIAGIAN ${ }^{2}$, \\ ANGGREYNI PRATIWI DANDURU ${ }^{2}$, CHRISTINA AVANTI ${ }^{2, \bullet}$ \\ ${ }^{1}$ Faculty of Biotechnology, Universitas Surabaya. J1. Ngagel Jaya Selatan No. 169, Surabaya 60294, East Java, Indonesia \\ ${ }^{2}$ Faculty of Pharmacy, Universitas Surabaya. Jl. Raya Kalirungkut, Surabaya 60293, East Java, Indonesia. Tel.: +62-31-2981110, Fax.: +62-31-298 1113, \\ "email: c_avanti@staff.ubaya.ac.id
}

Manuscript received: 27 February 2020. Revision accepted: 17 April 2020.

\begin{abstract}
Sukweenadi J, Yunita O, Setiawan F, Kartini, Siagian MT, Danduru AP, Avanti C. 2020. Antioxidant Activity Screening of Seven Indonesian Herbal Extract. Biodiversitas 21: 2062-2067. Kumis kucing (Orthosiphon stamineus), pegagan (Centella asiatica), seledri (Apium graveolens), kunyit (Curcuma domestica), temulawak (Curcuma xanthorrhiza), tempuyung (Sonchus arvensis) and meniran (Phyllanthus niruri) are herbs that commonly used in the Indonesia folk medicine. The constituents that responsible for several important biological activities are phenolic and flavonoid compounds which also possess antioxidant activity. Antioxidant activity of those seven Indonesian herbal extracts was evaluated using DPPH, ABTS and FRAP methods. The extraction was done with the reflux method by using $80 \%$ ethanol as a solvent. The total phenol and total flavonoids from each herbal extract were measured using FolinCiocalteu reagent and spectrophotometry. Antioxidant activity results by DPPH method on O. stamineus, C. asiatica, A. graveolens, C. domestica, . xanthorrhiza, S. arvensis, and P. niruri showed $I C_{50}$ value at 132; ND; 2221; 361; 538; 1118 ; and 102 ppm, respectively. Results from ABTS method, showed $I C_{50}$ value at 22; 1199; 169; 100; 82; 143; and 20 ppm respectively. While results from the FRAP method showed that the ethanolic extract of $P$. niruri at a concentration of $20 \mathrm{ppm}$ possesses the strongest antioxidant activity (17.41 ppm AEAC/ppm extract). The content of total phenolic compounds are 22.50; 0.67; 2.16; 11.40; 7.80; 7.22; and 2.62\% GAE, while the total flavonoid compounds were 19.88; 6.67; 4.06; 71.02; 34.62; 3.78; and 8.34\% QE, respectively. It can be concluded that ethanolic extract of $P$. niruri and $O$. stamineus obtain the highest antioxidant activity based on DPPH, ABTS and FRAP method.
\end{abstract}

Keywords: Antioxidants, DPPH, ABTS, FRAP

Abbreviations: ABTS: 2,2'-azino-bis: 3-ethylbenzothiazoline-6-sulfonic acid, AEAC: Ascorbic acid equivalent antioxidant capacity, DPPH: 2,2-diphenylpicrylhydrazyl, FRAP: ferric reducing antioxidant power, GAE: Gallic acid equivalent, $I C_{50}$ : half maximal inhibitory concentration, QE: Quercetin equivalent, ROS: reactive oxygen species

\section{INTRODUCTION}

A free radical is a relatively unstable molecule having one unpaired electron in its outermost orbit. As it is highly reactive, a free radical is trying to reach a stable state by attracting electron from other molecules or cells in the body. The ability of a free radical molecule to oxidize other substances may cause oxidative damage in the body. A notable example of a free radical is the reactive oxygen species (ROS). ROS can react with and disrupt macromolecules, such as proteins, lipids, and nucleic acids in the human body. If the damage caused by ROS cannot be stopped, it will cause oxidative stress (Schieber and Chandel 2014).

Oxidative stress is an imbalance between free radicals and antioxidants in the body that are triggered by an excess of free radicals and a lack of antioxidants. Oxidative stress can cause oxidative damage starting from cells, tissues, to organs. Oxidative stress also generates accelerated aging (Kunwar and Priyadarsini, 2011). The sources of free radicals are endogenous and exogenous. Endogenous free radicals are produced intracellularly from automatic oxidation or inactivation of small molecules such as mitochondria, whereas exogenous free radicals are obtained from cigarette smoke, environmental pollutants, drugs, organic solvents, and pesticides (Rao et al. 2011).

An antioxidant is a chemical compound that donates an electron to an unpaired free radical, hence reduces the oxidation effect of a free radical. There are numerous compounds from herbs that can be used as natural exogenous antioxidants and clinically proven to be effective as antioxidants (Amorati and Valgimigli 2018). One of the chemical compounds is a phenolic compound, secondary metabolites which protect plants' organs from oxidation. Therefore, the phenolic compound is referred to as a natural antioxidant. In addition to its activity as an antioxidant, a phenolic compound in plants is known to have anticarcinogenic, anti-microbial, anti-allergic, anti-mutagenic, and anti-inflammatory properties (Schiavano et al. 2015; Babbar et al. 2015; Cirmi et al. 2017; Hoxha et al. 2015).

Other phytochemicals that possess antioxidant activity are flavonoids. Flavonoids are polyphenolic compounds contained in various plant species and have been useful in maintaining human health. Flavonoids in fruits and vegetables, which are routinely consumed can reduce the risk of cardiovascular disease (Ivey et al. 2017). The distribution and composition of phenolic content are very dependent on maturity, cultivars, horticultural practices, 
geographic origin, growing season, post-harvest storage conditions, and processing procedures (Kumar et al. 2019; Yoo and Moon 2016; Kim et al. 2018). Several studies reported that flavonoids affect many pharmacological activities, including antioxidant, anti-cancer, enzyme inhibitor, and anti-inflammatory agents (Aslani and Ghobadi 2016). The biological activities of flavonoids vary greatly, however, the benefit that is almost shared by all groups of flavonoids is the antioxidant activity. The structure of flavonoids is responsible for giving several mechanisms to antioxidant activity, such as radical scavenging and metal ion chelation (Pandey et al. 2012). Some flavonoids also inhibit enzymes that participate in ROS generation (Kumar and Pandey 2013).

Orthosiphon stamineus is usually used as an herbal medicine for gout, rheumatism, hematuria, albuminuria, hypertension, diabetes and diuretics (Alshawsh et al. 2012). Centella asiatica possesses various benefits including antibacterial agents, lowering blood sugar levels, lowering blood pressure, reducing liver inflammation, reducing fever, overcoming intestinal worms, increasing appetite, stimulating hair growth, and cleanse the blood (Mala and Tulika 2014). A. graveolens is used traditionally, as a booster for digestive enzymes or as an appetite enhancer, lowering blood pressure, diuretics, reducing pain in rheumatism, as well as anti-seizure medications and stomach pain alleviation. A. graveolens also has many other benefits, such as a blood purifier, repairing disturbed hormones, and removing uric acid through urine (Ishaq et al. 2016). The compounds contained in C. domestica such as curcuminoids and essential oils has an important role as antioxidants, anti-tumor, anti-cancer, anti-microbial, anticholesterol, anti-inflammatory. The antioxidant properties of $C$. domestica have been widely accepted as one of the spices with the highest antioxidant activity because they contain curcumin compounds in it. In several countries, including Indonesia, $C$. domestica is used as a treatment for a variety of respiratory disorders such as asthma, allergies, other than that it can be used for liver disorders, anorexia, rheumatism, colds, coughs and wound healing (Hewlings and Kalman 2017). Curcuma xanthorrhiza is used to increase appetite, improve digestive function, overcome impaired liver function, reduce joint and bone pain, reduce blood fat, antioxidants, and inhibit blood clotting. Its essential oils are reported as an effective anti-fungal and anti-bacterial agent (Rahmayunita et al. 2016). Sonchus arvensis has the potential to overcome hyperuricemia and destroys kidney stones that are known to be caused by the results of active compounds which are antioxidants. It is commonly used to treat bruises by affixing them to bruised parts, hemorrhoids, anti-inflammatory, relieve aches and rheumatism (Seal 2016). Phyllanthus niruri has many benefits such as anti-inflammatory, hepatoprotective, increase endurance, antidiarrheal, also as medication for cough, thrush, and heartburn (Twahirwa et al. 2018).

In this study, we determined the total phenolic compounds and total flavonoid compounds (FolinCiocalteau method) of seven Indonesian herbal plant extract; there are O. stamineus, C. asiatica, A. graveolens, C. domestica, C. xanthorrhiza, S. arvensis, and P. niruri. The morphological appearance of those herbs is shown in Figure 1. All extraction processes were done by the reflux method with $80 \%$ ethanol as the solvent. Antioxidant activity test was carried out by using DPPH, ABTS, and FRAP method. The present data would certainly help to explore the potency of the tested Indonesia herbal extract as a potential source of natural antioxidants to be used for pharmaceutical, nutraceutical, and functional food formulations. However, further research is needed to purify and identify the specific compounds that possess antioxidant properties, thus can be developed further on its applications for food and pharmaceutical industries.
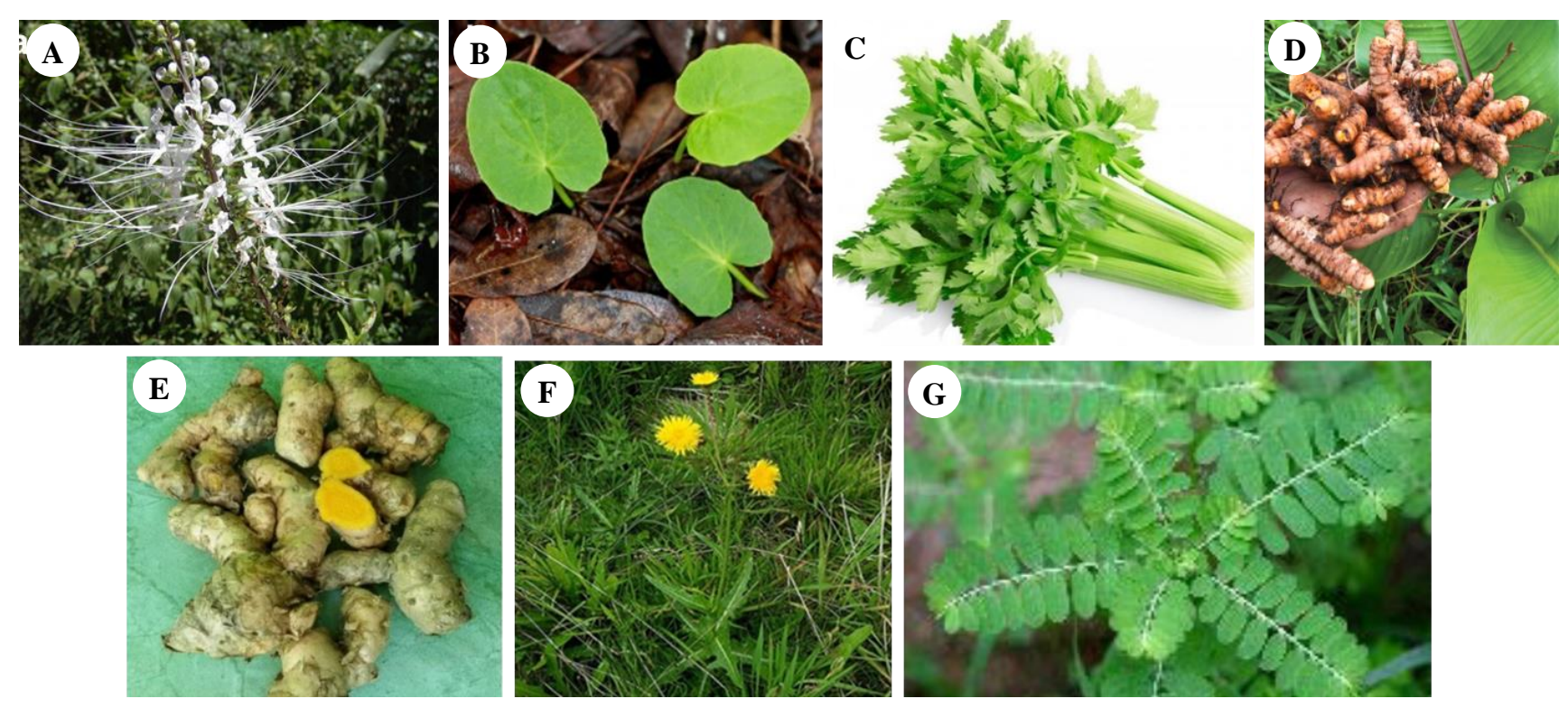

Figure 1. Morphological appearance of seven herbal plants: A. Orthosiphon stamineus; B. Centella asiatica; C. Apium graveolens; D. Curcuma domestica; E. Curcuma xanthorrhiza; F. Sonchus arvensis; G. Phyllanthus niruri 


\section{MATERIALS AND METHODS}

\section{Research materials}

Orthosiphon stamineus, C. asiatica, A. graveolens, C. domestica, C. xanthorrhiza, S. arvensis, and P. niruri herbal crude drugs were obtained from the Center for Research and Development of Medicines and Traditional Medicine (Balai Besar Penelitian dan Pengembangan Tanaman Obat dan Obat Tradisional), Tawangmangu, Central Java, Indonesia.

\section{Extraction method}

100 grams of crude herbal powder was added by 200 $\mathrm{mL}$ of $80 \%$ ethanol before the extraction process using reflux for 3 times 2 hours. Each extract was then evaporated using a rotary evaporator to obtain a viscous ethanol extract (Shi et al. 2005).

\section{Quantification of total phenol and total flavonoid Standard Curve of Gallic Acid}

Twenty-five $\mathrm{mg}$ gallic acid was dissolved in $25 \mathrm{~mL}$ of distilled water to obtain $1000 \mathrm{ppm}$ of gallic acid solution. This solution was then diluted into five different concentrations ( 2 ppm, 4 ppm, 6 ppm, 8 ppm, and 10 ppm). Each concentration was pipetted as much as $0.5 \mathrm{~mL}$ and put into a $10 \mathrm{~mL}$ volumetric flask, then $0.5 \mathrm{~mL}$ of FolinCiocalteu reagent was added in a ratio of $1: 1$. The flask was shaken until homogeneous for one minute and then allowed to stand. Four $\mathrm{mL}$ of $7.5 \% \mathrm{Na}_{2} \mathrm{CO}_{3}$ followed by distilled water until $10.0 \mathrm{~mL}$ was added prior to the eight minutes incubation. The absorbance measurements were carried out on a gallic acid solution by using a UV-VIS spectrophotometer at a maximum wavelength of $760 \mathrm{~nm}$ (Kamtekar et al. 2014). Three replications were performed on each gallic acid concentration.

\section{Determination of total phenol content}

Ten mg of each herbal plant ethanol extract was dissolved in $10 \mathrm{~mL}$ of distilled water. Then, $0.5 \mathrm{~mL}$ of herbal extract solution was added with $0.5 \mathrm{~mL}$ of FolinCiocalteu reagent (1:1 ratio), shaken until homogeneous for one minute and allowed to stand. Before the eighth minute incubation, $4 \mathrm{~mL}$ of $7.5 \% \mathrm{Na}_{2} \mathrm{CO}_{3}$ was added, followed by distilled water until $10 \mathrm{~mL}$. Then the measurements were carried out on the sample solution using a UV-Vis spectrophotometer with a wavelength of $760 \mathrm{~nm}$. Three replications were performed on each extract.

\section{Standard curve of quercetin}

$25 \mathrm{mg}$ of quercetin was dissolved in $25 \mathrm{~mL}$ of ethanol to obtain a $1000 \mathrm{ppm}$ of quercetin standard solution. The standard solution was diluted into five different concentrations (5 ppm, $10 \mathrm{ppm}, 15 \mathrm{ppm}, 20 \mathrm{ppm}$, and 25 ppm). Each solution was pipetted $0.05 \mathrm{~mL} ; 0.1 \mathrm{~mL} ; 0.15$ $\mathrm{mL} ; 0.2 \mathrm{~mL} ; 0.25 \mathrm{~mL}$, and put into a $10 \mathrm{~mL}$ volumetric flask. Then, $4 \mathrm{~mL}$ of distilled water was added, followed by $0.3 \mathrm{~mL}$ of $5 \% \mathrm{NaNO}_{2}$ reagent addition. After five minutes, $0.3 \mathrm{~mL}$ of $\mathrm{AlCl}_{3}$ was added and then $2 \mathrm{~mL}$ of $1 \mathrm{M} \mathrm{NaOH}$ was added in the sixth minute. The distilled water was added up to $10 \mathrm{~mL}$. The solution was shaken until homogeneous, then absorbance measurements of quercetin standard solutions were carried out by using a UV-Vis spectrophotometer with a wavelength of $415 \mathrm{~nm}$ (Kamtekar et al. 2014). Three replications were performed on each concentration.

\section{Determination of total flavonoid content}

Ten $\mathrm{mg}$ of each herbal plant ethanol extract was dissolved in $10 \mathrm{~mL}$ distilled water. $0.3 \mathrm{~mL}$ each solution was added with $0.3 \mathrm{~mL}$ of $5 \% \mathrm{NaNO}_{2}$ reagent (1:1 ratio). After five minutes of incubation, $0.3 \mathrm{~mL}$ of $\mathrm{AlCl}_{3}$ was added and in the sixth minute, $2 \mathrm{~mL}$ of $1 \mathrm{M} \mathrm{NaOH}$ was added. The distilled water was added until the volume of $10 \mathrm{~mL}$ was reached. The solution was shaken until homogeneous, then measurements were taken on the sample solution by using a UV-Vis spectrophotometer with a wavelength of $415 \mathrm{~nm}$. Three replications were performed on each extract.

\section{Antioxidant activity test with DPPH method}

The DPPH method was conducted according to the previous method reported by Fidrianny et al (2018) with slight modifications. The vitamin $\mathrm{C}$ standard solution was prepared by dissolving $5 \mathrm{mg}$ of vitamin $\mathrm{C}$ powder in ethanol up to $50 \mathrm{~mL}$ volume to obtain a vitamin $\mathrm{C}$ solution with a concentration of $100 \mathrm{ppm}$. The solution was then diluted to obtain five different concentrations $(10,20,30$, 40 , and $50 \mathrm{ppm}$ ) to create a calibration curve. The sample solution was prepared by dissolving $25 \mathrm{mg}$ herbal extract with ethanol in a $25 \mathrm{~mL}$ volumetric flask (1000 ppm). The sample solution was diluted into four concentrations (200, 400,600 , and $800 \mathrm{ppm}$ ). Each standard or sample solution was pipetted and the $0.05 \%$ of DPPH solution was added with a ratio of 1:3. The mixture was placed into a 96-well microplate reader after being homogeneously shaken. All solutions then were being incubated in a dark place at room temperature for 30 minutes. Free radical scavenging activity was calculated using the following formula:

$$
\text { DPPH scavenging effect }(\%)=\left[\frac{A_{B}-A_{A}}{A_{B}}\right] \times 100
$$

where, $A_{B}=$ absorbance of DPPH solution $(t=0$ min); $A_{A}=$ absorbance of tested extract solution $(t=30 \mathrm{~min})$. The concentration of extract or standard which exhibited 50\% radical scavenging $\left(\mathrm{IC}_{50}\right.$ value) was deduced from the linear regression of concentration versus the percentage of inhibition.

\section{Antioxidant activity test with the ABTS method}

The ABTS method was conducted by following the previous method developed by Dasgupta et al. (2015) with slight modification. $19.2 \mathrm{mg}$ of ABTS and $3.31 \mathrm{mg}$ of potassium persulfate were weighed separately. Each of them was then dissolved in $5 \mathrm{~mL}$ ethanol to obtain $7 \mathrm{mM}$ ABTS solution and $2.45 \mathrm{mM}$ potassium persulfate solution. In order to make ABTS reagent, the two solutions were mixed and incubated for 12-16 hours in a dark place at 
room temperature. $50 \mathrm{mg}$ of vitamin $\mathrm{C}$ was dissolved in $100 \mathrm{~mL}$ of distilled water (500 ppm) and serial dilution (10, $15,20,30,40$, and $50 \mathrm{ppm}$ ) was prepared. Ten $\mathrm{mg}$ of each plant extract was dissolved in $25 \mathrm{~mL}$ of ethanol (400 ppm) and diluted into 50, 100, 150, 200, and $250 \mathrm{ppm}$. ABTS test was carried out on a 96-well-microplate. The ABTS reagent and sample solution or standard solution (vitamin C) were pipetted in a volume ratio of 1:4, then placed into 96-well-microplate. The absorbance was measured by using a microplate reader at a wavelength of $734 \mathrm{~nm}$. The percentage of inhibition of ABTS oxidation was calculated using the following formula:

$$
\text { ABTS scavenging effect }(\%)=\left[\frac{A_{B}-A_{A}}{A_{B}}\right] \times 100
$$

Where: $\mathrm{A}_{\mathrm{B}}=$ absorbance of $\mathrm{ABTS}$ reagent; $\mathrm{A}_{\mathrm{A}}=$ absorbance of sample or standard. The concentration of extract or standard which exhibited $50 \%$ radical scavenging $\left(\mathrm{IC}_{50}\right.$ value) was deduced from the linear regression of concentration versus the percentage of inhibition.

\section{Antioxidant activity test with FRAP method}

FRAP solution was prepared by weighing $187 \mathrm{mg}$ sodium acetate trihydrate, $270 \mathrm{mg}$ ferric chloride $\left(\mathrm{FeCl}_{3} \cdot 6 \mathrm{H}_{2} \mathrm{O}\right)$, and $150 \mathrm{mg}$ TPTZ. Sodium acetate trihydrate powder was added with $16 \mathrm{~mL}$ acetic acid $(\mathrm{pH}$ 3.6) and dissolved in $250 \mathrm{~mL}$ of distilled water, $\mathrm{FeCl}_{3} \cdot 6 \mathrm{H}_{2} \mathrm{O}$ powder was dissolved in $100 \mathrm{~mL}$ of distilled water, whereas TPTZ was dissolved in $40 \mathrm{mM} \mathrm{HCl}$ up to $50 \mathrm{~mL}$. FRAP reagent was prepared by mixing $25 \mathrm{~mL}$ of sodium acetate trihydrate solution, $2.5 \mathrm{~mL}$ of $20 \mathrm{mM}$ $\mathrm{FeCl}_{3} \cdot 6 \mathrm{H}_{2} \mathrm{O}$ solution, $2.5 \mathrm{~mL}$ of $10 \mathrm{mM}$ TPTZ solution and then adding distilled water up to $100 \mathrm{~mL}$ (Hendra et al. 2011). A series concentration of vitamin $C(1.25,2.5,10,20$, 30 , and $40 \mathrm{ppm}$ ) was used as standard. The sample solution was prepared by dissolving each extract in ethanol and diluting it to a concentration of 200, 400,600, and $800 \mathrm{ppm}$. The FRAP reagent and sample solution or standard solution (vitamin C) were pipetted in a volume ratio of $1: 1$, then placed into 96-well-microplate. The absorbance was measured by using a microplate reader at a wavelength of $593 \mathrm{~nm}$.

\section{RESULTS AND DISCUSSION}

One of the parameters affecting the extract quality is the percentage of extract yield. The yield percentage was obtained by calculating the weight of viscous extract divided by the weight of crude herbs used. The yield percentage of seven Indonesian herbs extract produced from the reflux extraction method using $80 \%$ ethanol ranged from 8.76 to $37.50 \%$ as shown in Table 1. The reflux method was preferred because it widely used in herbal industries as it is efficient, easy to operate and costeffective. The extraction solvent is renewed in the extraction, the mass transfer driving force is greater, which leads to a shorter extraction time. The reuse of the solvent in the extraction also decreases the amount of solvent needed (Wang et al. 2013).
Table 2. Total phenol and total flavonoid content of seven herbal extracts

\begin{tabular}{lcc}
\hline \multicolumn{1}{c}{ Extract } & $\begin{array}{c}\text { Total phenol } \\
\text { content } \\
(\% \mathbf{G A E}) *\end{array}$ & $\begin{array}{c}\text { Total flavonoid } \\
\text { content } \\
(\boldsymbol{\%} \mathbf{Q E}) * *\end{array}$ \\
\hline Orthosiphon stamineus & $22.50 \pm 0.91$ & $19.88 \pm 0.91$ \\
Centella asiatica & $0.67 \pm 0.03$ & $4.06 \pm 0.27$ \\
Apium graveolens & $2.16 \pm 0.05$ & $6.67 \pm 0.31$ \\
Curcuma domestica & $11.40 \pm 0.66$ & $71.02 \pm 0.48$ \\
Curcuma xanthorrhiza & $7.80 \pm 0.39$ & $34.62 \pm 1.58$ \\
Sonchus arvensis & $7.22 \pm 0.15$ & $3.78 \pm 0.01$ \\
Phyllanthus niruri & $2.62 \pm 0.06$ & $8.34 \pm 0.74$ \\
\hline
\end{tabular}

Note: ${ }^{*} \mathrm{GAE}=$ Gallic Acid Equivalent; Linear Regression of Gallic acid standard curve: $y=0.0349+0.10095 x$, with $r^{2}=$ 0.9892; ** $\mathrm{QE}=$ Quercetin Equivalent; Linear Regression of quercetin standard curve: $\mathrm{y}=0.0722+0.02564 \mathrm{x}$, with $\mathrm{r}^{2}=0.9993$; Values in the column represent average \pm SD of 3 determinations

Table 1. The yield of seven crude drugs after $80 \%$ ethanol extraction by reflux

\begin{tabular}{|c|c|c|c|}
\hline \multirow[b]{2}{*}{ Crude drug } & \multirow[b]{2}{*}{$\begin{array}{c}\text { Weight } \\
\text { (g) }\end{array}$} & \multicolumn{2}{|c|}{ Extract } \\
\hline & & $\begin{array}{c}\text { Weight } \\
\text { (g) }\end{array}$ & $\begin{array}{c}\text { Yield } \\
(\%)\end{array}$ \\
\hline Orthosiphon stamineus & 105.20 & 9.22 & 8.76 \\
\hline Centella asiatica & 101.03 & 9.33 & 9.23 \\
\hline Apium graveolens & 103.12 & 33.82 & 33.80 \\
\hline Curcuma domestica & 101.30 & 28.00 & 27.64 \\
\hline Curcuma xanthorrhiza & 100.30 & 17.50 & 17.45 \\
\hline Sonchus arvensis & 100.70 & 17.90 & 17.78 \\
\hline Phyllanthus niruri & 66.90 & 25.10 & 37.50 \\
\hline
\end{tabular}

The previous study also reported that the extract yield and the antioxidant activity of herbal extract produced by the reflux method were higher among other methods, regardless of the extraction solvent (Sultana et al. 2009). The extraction efficiency is influenced by various factors such as temperature, solvent type, duration of extraction and solid to liquid ratio, of which the solvent greatly affects the extraction yield and chemical compound of the extracts (Choung et al. 2014). Ethanol was selected since it has a hydroxyl group that is polar and an alkyl group that is nonpolar in its structure, therefore ethanol can extract compounds with various polarities and is easily evaporated. The $80 \%$ concentration of ethanol in water is an ideal solution as it was also reported that the aqueous solvent provides better yield than the absolute organic solvent (Sultana et al. 2009; Choung et al. 2014).

Phenolic and flavonoid compounds are generally found in all parts of the plant. This compound is a group of secondary metabolites consists of a large group of polyphenols that can scavenge free radicals and inhibit lipid oxidation (Kamtekar et al. 2014). Therefore, the measurement of phenol and flavonoid contents is important to predict the antioxidant power of each extract. The differences in total phenol and flavonoids content of each plant (Table 2) can be caused by several factors, such as geographical origin, plant maturity, environmental factors (temperature, ultraviolet light, $\mathrm{CO}_{2}$ levels in the atmosphere), and the solvents used in the extraction 
process. As part of phenolic compounds, total flavonoid content should be lower than the total phenolic content. However, some of the results in this study expressed otherwise. Typical phenolic compounds that possess antioxidant activity are known to be mainly phenolic acids and flavonoids. It seems that the total phenolic content measured by the Folin-Ciocalteu procedure does not give a full picture of the quantity of the phenol constituents in the plant extracts, as Folin-Ciocalteu reagent and its gallic acid standard will only determine the phenolic acids. Phenolic acids are a major class of phenolic compounds, widely occurring in the plant kingdom especially in fruits and vegetables (Katsube et al. 2004; Wu et al. 2004).

As the first step of antioxidant activity screening, seven herbal extracts were determined with a free radical scavenging method against stable DPPH (1,1-diphenyl-2picrylhydrazyl). DPPH is the most commonly used free radical in the antioxidant screening assay. It has an unpaired electron from the nitrogen atom. When a compound or material with the capability to donate hydrogen is reacted with the DPPH, it will transform DPPH into DPPH-H (1,1-diphenyl-2-picrylhydrazyl). According to (Molyneux 2004), a compound is classified as very strong when the $\mathrm{IC}_{50}$ value is $<50 \mathrm{ppm}$, strong when the $\mathrm{IC}_{50}$ value is $50-100 \mathrm{ppm}$, moderate when the $\mathrm{IC}_{50}$ value is 101-150 ppm, and weak antioxidants when the $\mathrm{IC}_{50}$ value is $>150$ ppm. As shown in Table 3, $P$. niruri and $O$. stamineus extract showed moderate antioxidant activity according to the aforementioned categories.

Table 3. Antioxidant activity of seven herbal extracts determined by DPPH method

\begin{tabular}{ll}
\hline \multicolumn{1}{c}{ Herbal extract } & IC $_{\mathbf{5 0}}(\mathbf{p p m})$ \\
\hline Orthosiphon stamineus & $132 \pm 6.6$ \\
Centella asiatica & ND \\
Apium graveolens & $2221 \pm 61.8$ \\
Curcuma domestica & $361 \pm 9.7$ \\
Curcuma xanthorriza & $538 \pm 12.8$ \\
Sonchus arvensis & $1118 \pm 7.1$ \\
Phyllanthus niruri & $102 \pm 1.7$ \\
Vitamin C* & $31 \pm 1.6$ \\
\hline
\end{tabular}

Note: * standard compound; ND: not detected; Results are presented as mean \pm SD of IC 50 (inhibitory concentration 50, $n=$ 4)

Table 4. Antioxidant activity of seven 7 herbal extracts determined by ABTS method

\begin{tabular}{ll}
\hline \multicolumn{1}{c}{ Herbal extract } & \multicolumn{1}{c}{ IC $_{\mathbf{5 0}}(\mathbf{p p m})$} \\
\hline Orthosiphon stamineus & $22 \pm 2.99$ \\
Centella asiatica & $1199 \pm 4.41$ \\
Apium graveolens & $169 \pm 1.51$ \\
Curcuma domestica & $100 \pm 3.02$ \\
Curcuma xanthorriza & $82 \pm 3.06$ \\
Sonchus arvensis & $143 \pm 1.85$ \\
Phyllanthus niruri & $20 \pm 3.59$ \\
Vitamin C* & $9 \pm 1.90$ \\
\hline Note: $*$ standard compound; Results are presented as mean \pm SD \\
of IC IC $_{50}$ (inhibitory concentration 50, $\left.n=4\right)$
\end{tabular}

Table 5. Antioxidant activity of seven herbal extracts determined by FRAP method

\begin{tabular}{|c|c|c|}
\hline Herbal extract & $\begin{array}{c}\text { Concentration } \\
(\text { ppm) }\end{array}$ & $\begin{array}{c}\text { Antioxidant activity } \\
\text { (ppm AEAC/ ppm } \\
\text { extract) }\end{array}$ \\
\hline Orthosiphon & 50 & $6.92 \pm 0.34$ \\
\hline \multirow[t]{4}{*}{ stamineus } & 100 & $10.40 \pm 0.77$ \\
\hline & 150 & $14.38 \pm 0.39$ \\
\hline & 200 & $16.49 \pm 1.03$ \\
\hline & 250 & $18.39 \pm 0.89$ \\
\hline \multirow[t]{5}{*}{ Centella asiatica } & 200 & $1.77 \pm 0.09$ \\
\hline & 400 & $2.42 \pm 0.15$ \\
\hline & 600 & $2.86 \pm 0.13$ \\
\hline & 800 & $3.59 \pm 0.14$ \\
\hline & 1000 & $3.84 \pm 0.27$ \\
\hline \multirow{4}{*}{ Apium graveolens } & 200 & $5.39 \pm 0.06$ \\
\hline & 400 & $8.36 \pm 0.28$ \\
\hline & 600 & $8.81 \pm 0.29$ \\
\hline & 800 & $10.26 \pm 0.50$ \\
\hline \multirow[t]{5}{*}{ Curcuma domestica } & 200 & $18.15 \pm 0.60$ \\
\hline & 400 & $28.57 \pm 1.37$ \\
\hline & 600 & $33.88 \pm 1.28$ \\
\hline & 800 & $47.29 \pm 1.19$ \\
\hline & 1000 & $50.74 \pm 0.68$ \\
\hline \multirow[t]{5}{*}{ Curcuma xanthorrhiza } & 200 & $5.42 \pm 0.16$ \\
\hline & 400 & $10.33 \pm 0.28$ \\
\hline & 600 & $11.99 \pm 0.71$ \\
\hline & 800 & $14.71 \pm 0.53$ \\
\hline & 1000 & $16.89 \pm 0.46$ \\
\hline \multirow[t]{5}{*}{ Sonchus arvensis } & 200 & $27.88 \pm 0.31$ \\
\hline & 400 & $47.63 \pm 0.89$ \\
\hline & 600 & $54.61 \pm 0.36$ \\
\hline & 800 & $61.02 \pm 1.32$ \\
\hline & 1000 & $63.68 \pm 0.63$ \\
\hline \multirow[t]{5}{*}{ Phyllanthus niruri } & 20 & $17.41 \pm 0.83$ \\
\hline & 40 & $27.50 \pm 2.07$ \\
\hline & 60 & $42.25 \pm 0.18$ \\
\hline & 80 & $52.25 \pm 2.78$ \\
\hline & 100 & $60.10 \pm 1.50$ \\
\hline
\end{tabular}

Note: AEAC: Ascorbic acid equivalent antioxidant capacity; Results are presented as mean $\pm \mathrm{SD}(n=4)$

The determination of antioxidant activity by the ABTS method was obtained from the oxidation of potassium persulfate with ABTS salt. The principle of the ABTS method is the ability of antioxidant compounds to stabilize free radical compounds by donating proton radicals; it can be seen from the decrease in blue to no color. ABTS testing can be performed for lipophilic or hydrophilic compounds, with observations at a wavelength of $734 \mathrm{~nm}$. According to the results from the ABTS method shown in Table $4, P$. niruri and $O$. stamineus extract showed strong antioxidant activity.

The determination of antioxidant activity by the FRAP method has several advantages such as fast, easy and simple. This method involves the reduction reaction of the $\mathrm{Fe}^{3+}$ complex from tripyridyl-triazine $\mathrm{Fe}^{3+(\mathrm{TPTZ})}$ to the $\mathrm{Fe}^{2+}$ complex, $\mathrm{Fe}^{2+}$ (TPTZ) which is characterized by a change in color to blue. In the FRAP reagent, there is a mixture of TPTZ, $\mathrm{FeCl}_{3}$ and acetate buffer, so it can be said that the FRAP reagent is a colorless compound of $\mathrm{Fe}^{3+}-\mathrm{TPTZ}$. The addition of $\mathrm{FeCl}_{3}$ is used to form $\mathrm{Fe}^{3+}$ complex compounds. This method uses $\mathrm{pH} 3.6$ to facilitate the reduction process 
(Thaipong et al. 2006). The absorbance value obtained was measured using a microplate reader with a wavelength of $593 \mathrm{~nm}$. Both $P$. niruri and $O$. stamineus extract showed strong antioxidant activity categories according to the FRAP method (Table 5). Consistent results of potential moderate into strong antioxidant activity was shown by $P$. niruri and $O$. stamineus ethanolic extract by DPPH, ABTS, and FRAP method.

In conclusion, based on the results obtained from the determination of antioxidant activity using the DPPH, ABTS, and FRAP method, it can be concluded that the ethanolic extract of $P$. niruri and $O$. stamineus provided the highest antioxidant activity among seven Indonesian herbs involved in this study. Further research is needed to purify and identify the specific compounds that possess antioxidant properties of $P$. niruri and $O$. stamineus, to be applied for adjuvant therapy.

\section{ACKNOWLEDGMENTS}

This study was supported by Kementerian Riset dan Teknologi Republik Indonesia (Hibah Penelitian Dasar) [Ministry of Research and Technology Republic of Indonesia (Fundamental Research Grant)] in 2020, with the contract number: 030/SP-Lit/LPPM-01/RistekBRIN/Multi/ FF/III/2020.

\section{REFERENCES}

Schieber M, Chandel NS. 2014. ROS function in redox signaling and oxidative stress. Curr Biol 24 (10): 453-462.

Kunwar A, Priyadarsini KI. 2011. Free radicals, oxidative stress, and importance of antioxidants in human health. J Med Allied Sci. 1 (2): 53-60.

Rao PS, Kalva S, Yerramilli A, Mamidi S. 2011. Free radicals and tissue damage: Role of antioxidants. Free Radic Antiox 1 (4): 2-7.

Amorati R, Valgimigli L. 2018. Methods to measure the antioxidan activity of phytochemicals and plant extracts. J Agric Food Chem 66 (13): 3324-3329.

Schiavano GF, De Santi M, Brandi G, et al. 2015. Inhibition of breast cancer cell proliferation and in vitro tumorigenesis by a new red apple cultivar. PLoS One 10 (8): e0135840. DOI 10.1371/journal.pone. 0135840 .

Babbar N, Oberoi HS, Sandhu SK. 2015. Therapeutic and nutraceutical potential of bioactive compounds extracted from fruit residues. Crit Rev Food Sci Nutr 55 (3): 319-337.

Cirmi S, Maugeri A, Ferlazzo N, et al. 2017. Anticancer potential of citrus juices and their extracts: a systematic review of both preclinical and clinical studies. Front Pharmacol 8 (420): 1-11.

Hoxha L, Kongoli R, Hoxha M. 2015. Antioxidant Activity of Some Dried Autochthonous Albanian Fig (Ficus carica) Cultivars. Intl J Crop Sci Technol 1 (2): 20-26.

Ivey KL, Jensen MK, Hodgson JM, et al. 2017. Association of flavonoidrich foods and flavonoids with risk of all-cause mortality. Br J Nutr 117 (10): 1470-1477

Kumar D, Ram L, Ladaniya MS, Khadse A, Kumar S. 2019. Environmental impact on biochemical parameters during developmental stages of Citrus fruit. Indian J Hortic 76 (2): 253-258.

Yoo KM, Moon B. 2016. Comparative carotenoid compositions during maturation and their antioxidative capacities of three citrus varieties. Food Chem 196: 544-549.

Kim YJ, Joo SC, Shi J, et al. 2018. Metabolic dynamics and physiological adaptation of Panax ginseng during development. Plant Cell Rep 37 (3): $393-410$
Aslani BA, Ghobadi S. 2016. Studies on oxidants and antioxidants with a brief glance at their relevance to the immune system. Life Sci 146: 163-173.

Pandey AK, Mishra AK, Mishra A. 2012. Antifungal and antioxidative potential of oil and extracts derived from leaves of Indian spice plant Cinnamomum tamala. Cell Mol Biol. 58 (1): 142-147.

Kumar S, Pandey AK. 2013. Chemistry and biological activities of flavonoids: an overview. Sci World J 2013: 162750. DOI: $10.1155 / 2013 / 162750$.

Alshawsh MA, Abdulla MA, Ismail S et al. 2012. Free radical scavenging, antimicrobial and immunomodulatory activities of Orthosiphon stamineus. Molecules 17 (5): 5385-5395.

Mala A, Tulika T. 2014. Therapeutic efficacy of Centella asiatica (L.) and Momordica charantia: As traditional medicinal plant. J Plant Sci 3 (1): 1-9.

Ishaq H, Furqan M, Sheikh D, et al. 2016. Comparative study of ethanolic and aqueous extracts of Apium graveolens L.root with furosemide for its diuretic activity \& excretion of urinary metabolites in Wistar rats. Sci Intl 28 (3): 2503-2507.

Hewlings SJ, Kalman DS. 2017. Curcumin: a review of its' effects on human health. Foods 6 (10): E92. DOI: 10.3390/foods6100092.

Rahmayunita G, Jacoeb TN, Novianto E, et al. 2016. A double-blind randomized controlled trial of topical Curcuma xanthorrhiza Roxb. on mild psoriasis: clinical manifestations, histopathological features, and K6 expressions. Med J Indon 27 (3): 178-184.

Seal T. 2016. Quantitative HPLC analysis of phenolic acids, flavonoids and ascorbic acid in four different solvent extracts of two wild edible leaves, Sonchus arvensis and Oenanthe linearis of North-Eastern region in India. J Appl Pharm Sci 6 (2): 157-166.

Twahirwa A, Ndagijimana A, Mukazayire MJ, Nyombaire G, Kabera JN. 2018. Phyllantus niruri: Ethnobotany, Chemistry and Pharmacological properties towards drug formulations. Intl J Curr Res Life Sci 7 (9): 2652-2658.

Shi J, Nawaz H, Pohorly J, et al. 2005. Extraction of polyphenolics from plant material for functional foods-Engineering and technology. Food Rev intl 21 (1): 139-166

Kamtekar S, Keer V, Patil V. 2014. Estimation of phenolic content, flavonoid content, antioxidant and alpha-amylase inhibitory activity of marketed polyherbal formulation. J Appl Pharm Sci 4 (9): 61-65.

Fidrianny I, Anggraeni NA, Insanu M. 2018. Antioxidant properties of peels extract from three varieties of banana (Musa sp.) grown in West Java-Indonesia. Intl Food Res J 25 (1): 57-64.

Dasgupta N, Chowdhury P, Das S. 2015. Comparative adaptability assessment of two mangroves from Indian Sundarbans: some biochemical appearances. Nat Sci 7 (12): 519-534.

Hendra R, Ahmad S, Oskoueian E, Sukari A, Shukor MY. 2011. Antioxidant, anti-inflammatory and cytotoxicity of Phaleria macrocarpa (Boerl.) Scheff fruit. BMC Cmpl Altern Med 11: 110. DOI: $10.1186 / 1472-6882-11-110$

Wang DG, Liu WY, Chen GT. 2013. A simple method for the isolation and purification of resveratrol from Polygonum cuspidatum. J Pharmaceut Anal 3 (4): 241-247.

Sultana B, Anwar F, Ashraf M. 2009. Effect of extraction solvent/technique on the antioxidant activity of selected medicinal plant extracts. Molecules 14 (6): 2167-2180.

Choung MG, Hwang YS, Lee MS, et al. 2014. Comparison of extraction and isolation efficiency of catechins and caffeine from green tea leaves using different solvent systems. Intl J Food Sci Technol 49 (6): $1572-1578$.

Katsube T, Tabata H, Ohta Y, et al. 2004. Screening for antioxidant activity in edible plant products: comparison of low-density lipoprotein oxidation assay, DPPH radical scavenging assay, and Folin-Ciocalteu assay. J Agric Food Chem 52 (8): 2391-2396.

Wu X, Beecher GR, Holden JM, et al. 2004. Lipophilic and hydrophilic antioxidant capacities of common foods in the United States. J Agric Food Chem 52 (12): 4026-4037.

Marjoni MR, Zulfisa A. 2017. Antioxidant activity of methanol extract/fractions of senggani leaves (Melastoma candidum D. Don). Pharm Anal Acta 8: 557. 8:8 DOI: 10.4172/2153-2435.1000557.

Molyneux P. 2004. The use of the stable free radical diphenylpicrylhydrazyl (DPPH) for estimating antioxidant activity. J Sci Technol 26 (2): 211-219.

Thaipong K, Boonprakob U, Crosby K, Cisneros-Zevallos L, Byrne DH. 2006. Comparison of ABTS, DPPH, FRAP, and ORAC assays for estimating antioxidant activity from guava fruit extracts. J Food Compos Anal 19 (6-7): 669-675 